
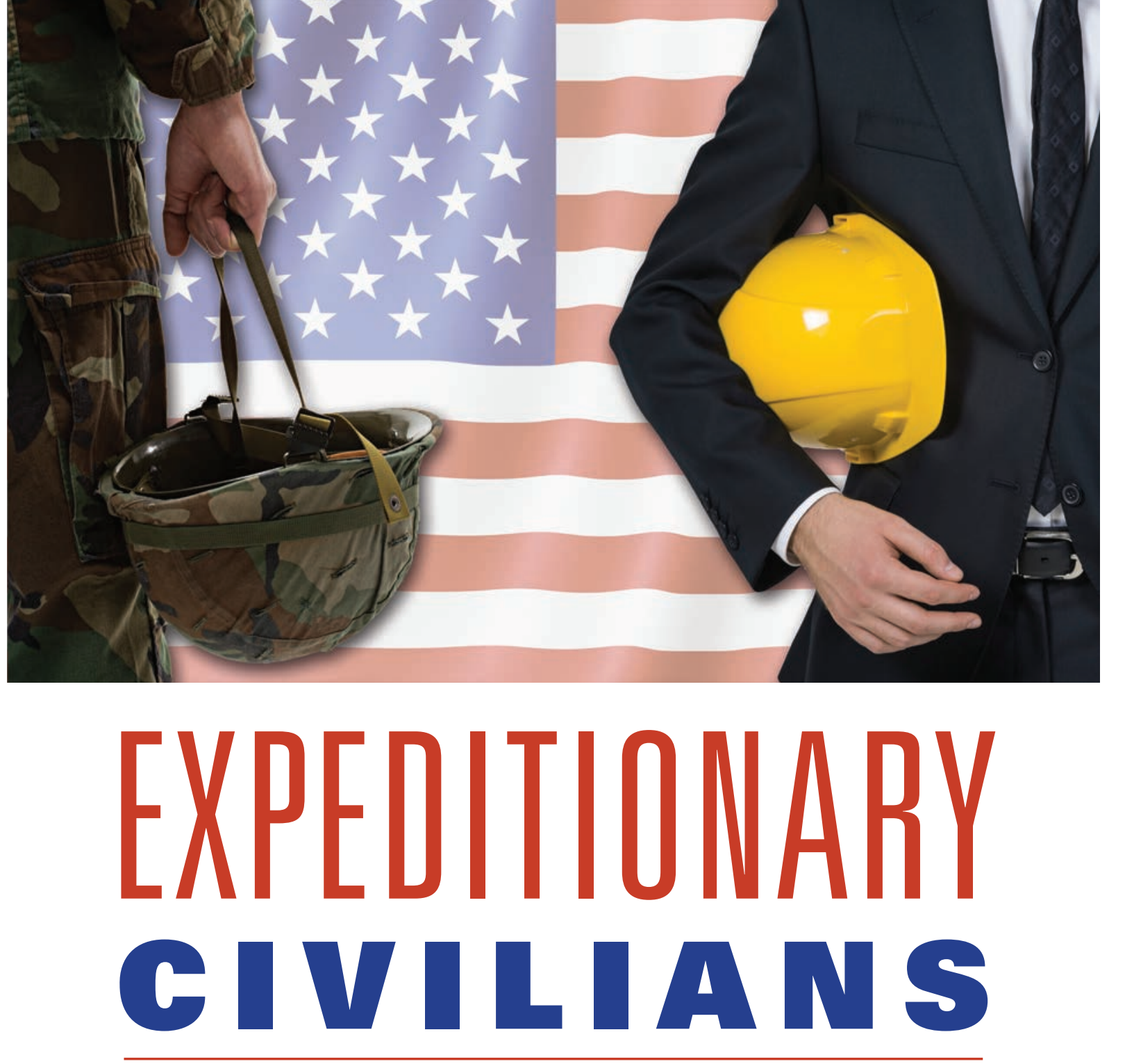

\title{
Informing Department of Defense Civilian Deployment Policy and Practice
}

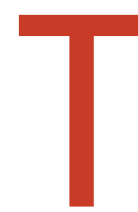

he U.S. Department of Defense (DoD) increasingly looked to its civilian workforce to fill critical needs overseas during Operations Iraqi Freedom and Enduring Freedom. The U.S. Department of State had been deploying small numbers of civilian personnel to fill Provincial Reconstruction Teams in Iraq, and it turned to DoD to help meet staffing demands during the military troop surge in 2007. The Office of the Secretary of Defense agreed that the approximately 700,000 -strong DoD civilian workforce was a viable source of deployable personnel and could help alleviate pressure on the uniformed military. DoD civilians began deploying in larger numbers, but it quickly became clear that demand for these personnel outstripped their supply.

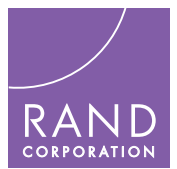


DoD faced several challenges in developing a sustainable cadre of deployable civilians. For example, there were few career-based incentives for civilians to volunteer or for their DoD employers to let them deploy. Responsibility for recruitment and training fell to the military services, which did not have consistent programs in place for these activities. To help address these challenges, DoD Directive 1404.10 established the DoD Civilian Expeditionary Workforce in 2009 with the goal of recruiting, training, and clearing 20,000-30,000 civilians who would be ready to deploy quickly when needed to support operations. The program office, under the direction of what is now the Office of the Deputy Assistant Secretary of Defense for Civilian Personnel Policy, encountered resource constraints as U.S. defense budgets tightened and the United States proceeded with its withdrawal from the conflicts in Iraq and Afghanistan. As a consequence, the directive is being revised, and the goal of a large-scale standing cadre of DoD expeditionary civilians was replaced by a more modest force of around 5,300.

Since that time, responsibility for sourcing DoD expeditionary civilian positions has shifted, with the U.S. Army and U.S. Central Command (USCENTCOM) each playing a role at various points. As efforts to establish an expeditionary civilian capability have evolved, it has become clear that there is a need for DoD to define its goals for a deployable civilian program and to address potential gaps in policies, procedures, and planning for future contingencies.

A RAND study explored how DoD could create a civilian deployment model that can respond to requirements as they arise-a model that would be viable ten to 20 years into the future. This involved an end-to-end review of existing DoD policy and guidance on all aspects of civilian deployment and a series of in-depth interviews with officials from U.S. and foreign government agencies that have

\section{SOURCING}

The term sourcing has two related meanings in the context of DoD civilian deployment. In its most basic sense, it refers to the provision by force providers of candidates for expeditionary civilian positions. However, sourcing also refers to the process of recruiting, screening, and selecting candidates for deployable positions. Sourcing is the first step in the process of filling expeditionary civilian positions. Readiness preparation (training, screening, and other predeployment activities) and tracking (monitoring during and after deployment) are the second and third steps in the civilian deployment process.

programs in place for deploying civilians. The research team also analyzed gaps between DoD policy and practice, U.S. combatant command requirements for deployable civilians, and options for DoD to move forward in developing a sustainable model to guide the use of expeditionary civilians.

\section{What Is the Need for DoD Expeditionary Civilians Across the Range of U.S. Military Operations?}

Since the creation of the Civilian Expeditionary Workforce in 2009, USCENTCOM has beenby far - the largest requestor of expeditionary civilian capabilities, generating 89 percent of requirements as of mid-2014. This is unsurprising, given that the concurrent conflicts in Iraq and Afghanistan fell within the USCENTCOM area of responsibility. High levels of demand for civilian capabilities in USCENTCOM may continue into the 
future, and it is possible that unforeseen demands will arise in other regions.

RAND's study was the first to examine combatant commands' need for and understanding of civilian expeditionary capabilities - and it found significant variation in perceptions. Key concerns among command staff included the amount of time needed to source civilian candidates and uncertainty about whether volunteers would be available and willing to deploy when needed. These factors led some combatant commands to view civilians as a less reliable option than military personnel to meet critical needs.

U.S. Northern Command (USNORTHCOM), which "deploys" its own civilians within the United States, did not have a need for DoD expeditionary civilians at the time of the study. However, it did not rule out the possibility in the future if it were possible to mobilize these personnel on very short notice. Both U.S. Southern Command (USSOUTHCOM) and U.S. Africa Command (USAFRICOM) identified a small number of requirements for civilian capabilities, including for logistics, intelligence, and cyber experts. Both commands have relied on DoD expeditionary civilians in the past but found the process administratively burdensome. Neither U.S. Pacific Command (USPACOM) nor U.S. European Command (USEUCOM) anticipated a need for expeditionary civilians at the time of the study.

\section{What Are the Goals of DoD's Civilian} Deployment Capability, and What Are the Challenges to Strengthening This Capability?

The impetus for the Civilian Expeditionary Workforce was to fill low-density, high-demand positions not easily filled by the uniformed military. In practice, expeditionary civilians were used to reduce stress on the uniformed military,

\section{U.S. Central Command has been the primary user of DoD expeditionary civilians}

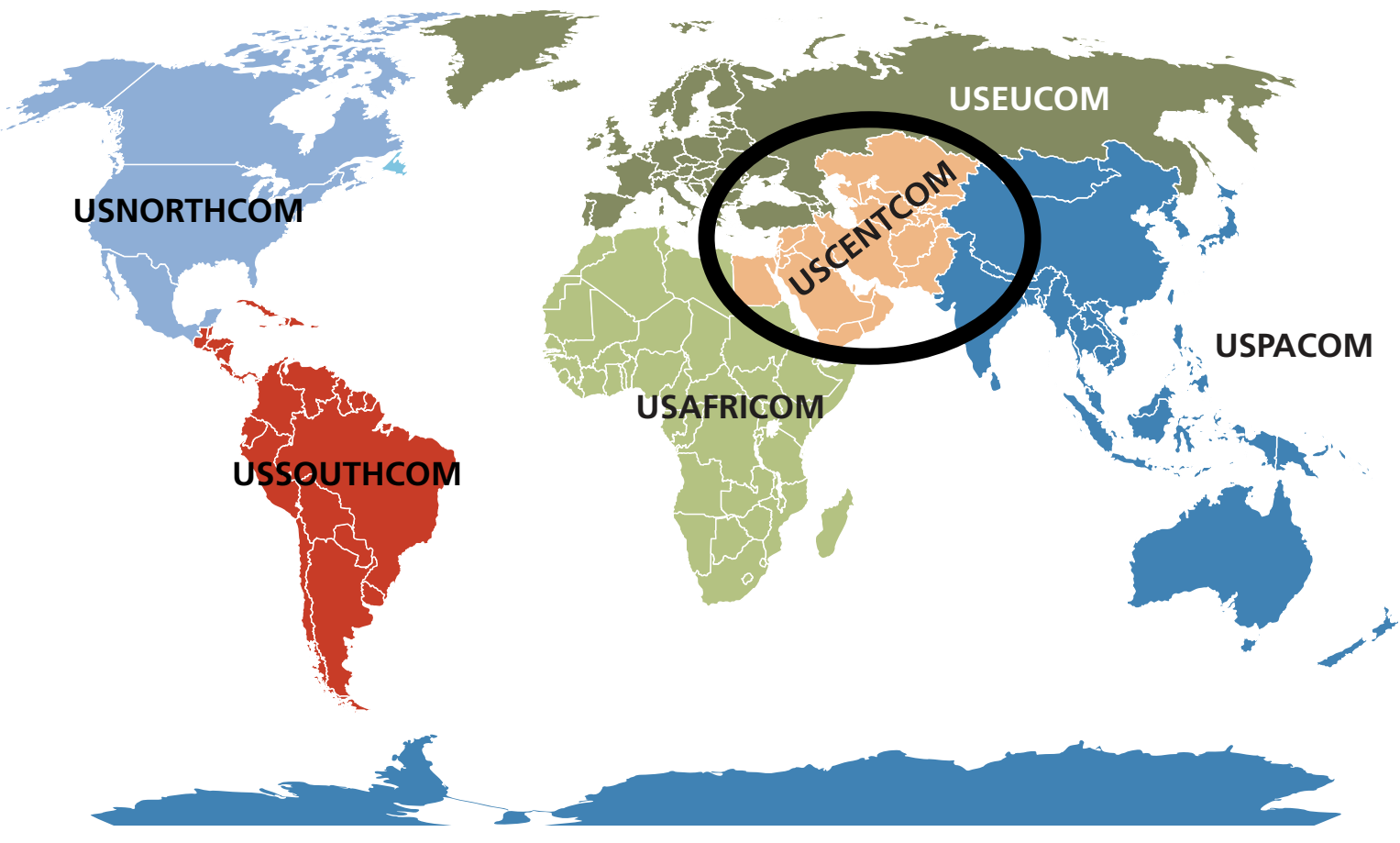


reduce the military's reliance on contractors, and circumvent limits on the deployment of additional uniformed military personnel. Since 2009, it appears that the bulk of DoD expeditionary civilians have performed jobs that could have been done by the military, had there been sufficient troop capacity.

DoD faces three policy considerations that reflect the motivation for an expeditionary civilian capability and may determine the long-term feasibility of the program.

\section{Ability to Work Across the Joint Workforce}

DoD civilians work for a particular military service or DoD agency (specifically, the Defense Intelligence Agency, Defense Logistics Agency, or the Defense Contract Management Agency). Civilians must apply to deploy with another organization, and their home office may be reluctant to allow them to leave. This may be especially true if there is limited capacity to backfill an individual's position. In addition, the home office must continue to pay the individual's salary while he or she is deployed. Finally, civilians may be reluctant to apply for deployable positions because switching to a different service or agency may hinder their career progression.

\section{Insourcing of Capabilities Previously Outsourced to Contractors}

In the mid-2000s, several high-profile incidents regarding contractor transparency, accountability, and overbilling in Iraq and Afghanistan called extensive outsourcing into question. DoD policy guidance states a preference for expeditionary civilians when they are available and cost-effective. However, the nature and scale of future contingencies may lead DoD to again rely on contractors to fulfill these needs.

\section{Relative Costs of Deploying Civilians, Military Personnel, and Contractors}

There has been little formal analysis comparing the cost to deploy a civilian with the cost to deploy military personnel or contractors. A better understanding of these relative costs across DoD would help policymakers and other officials determine the best circumstances under which to deploy civilians.

\section{What Civilian Deployment Models Do}

\section{U.S. and Foreign Government Organizations Employ, and What Insights Do They Offer for DoD?}

U.S. and foreign government agencies deploy civilians for a host of missions requiring the type of expertise found in civilian organizations, including technical assistance to military operations, humanitarian assistance/disaster relief, election monitoring, intelligence, security force training, institution building, and counterdrug, counterpiracy, and countergang activities. The research team reviewed civilian deployment policies and interviewed representatives from 17 organizations in the United States, Canada, the United Kingdom, the European Union, and Australia to determine how they meet requirements for expeditionary civilian capabilities.

The research team reviewed civilian deployment policies and interviewed representatives from 17 organizations in the United States, Canada, the United Kingdom, the European Union, and Australia. 
Agencies that deploy civilians rely on one or more of four models that differ along two parameters:

- Internal or external sourcing: Internal models draw on civilian capabilities within the deploying organization, while external models involve advertising positions and recruiting candidates from outside the organization.

- Reactive or proactive sourcing: Reactive models identify deployable civilians in response to a particular requirement, while proactive models rely on a preselected pool of candidates recruited either internally or externally.

There are advantages and disadvantages to each model. For example, an internal sourcing model allows an organization to retain full ownership of the skill set needed to meet a particular requirement, but these models also require organizations to temporarily backfill the jobs of civilians who deploy and then reintegrate personnel when they return. Organizations that use external sourcing models do not need to backfill civilian positions, but deployable civilians with the necessary skills may not be readily available outside the organization.

Reactive models can save costs by training and preparing civilians shortly before a deployment, and the training can be targeted to a particular mission. But this timing may prevent an organization from responding quickly to a requirement. Proactive models allow organizations to deploy civilians on short notice, but predeployment training and preparation are sunk costs that may not be recovered if forecasted requirements change. DoD could draw on a combination of models to meet requirements for expeditionary civilians. It may also benefit from pooling capabilities with other organizations, following the approach

\section{DoD could draw on a combination of models to meet requirements for expeditionary civilians.}

taken by some U.S. intelligence organizations. To source and deploy civilians rapidly, DoD will need to closely examine the speed with which the recruitment process must take place to determine whether it would be best served by establishing a preselected pool of deployable civilians or by making deployment part of the job description when hiring.

Planning for emerging requirements will also be important in optimizing the timelines for DoD civilian deployments and the size and scope of the deployable civilian workforce. For example, if a particular skill set will likely be in high demand in the future, DoD would benefit from developing and maintaining that skill set internally rather than seeking qualified candidates externally. Successful planning over the long term will depend on accurate forecasting methods and an enterprise-wide view of emerging requirements, as well as a reliable source of candidates. Finally, most of the organizations that RAND examined had well-defined policies that clearly articulated roles and responsibilities at each stage of the deployment process. Ensuring that such policies are in place will help improve understanding of the expectations for DoD expeditionary civilians, their employers, and combatant commanders. 


\section{DoD could adopt one or more of four models to identify and prepare civilians for deployment}

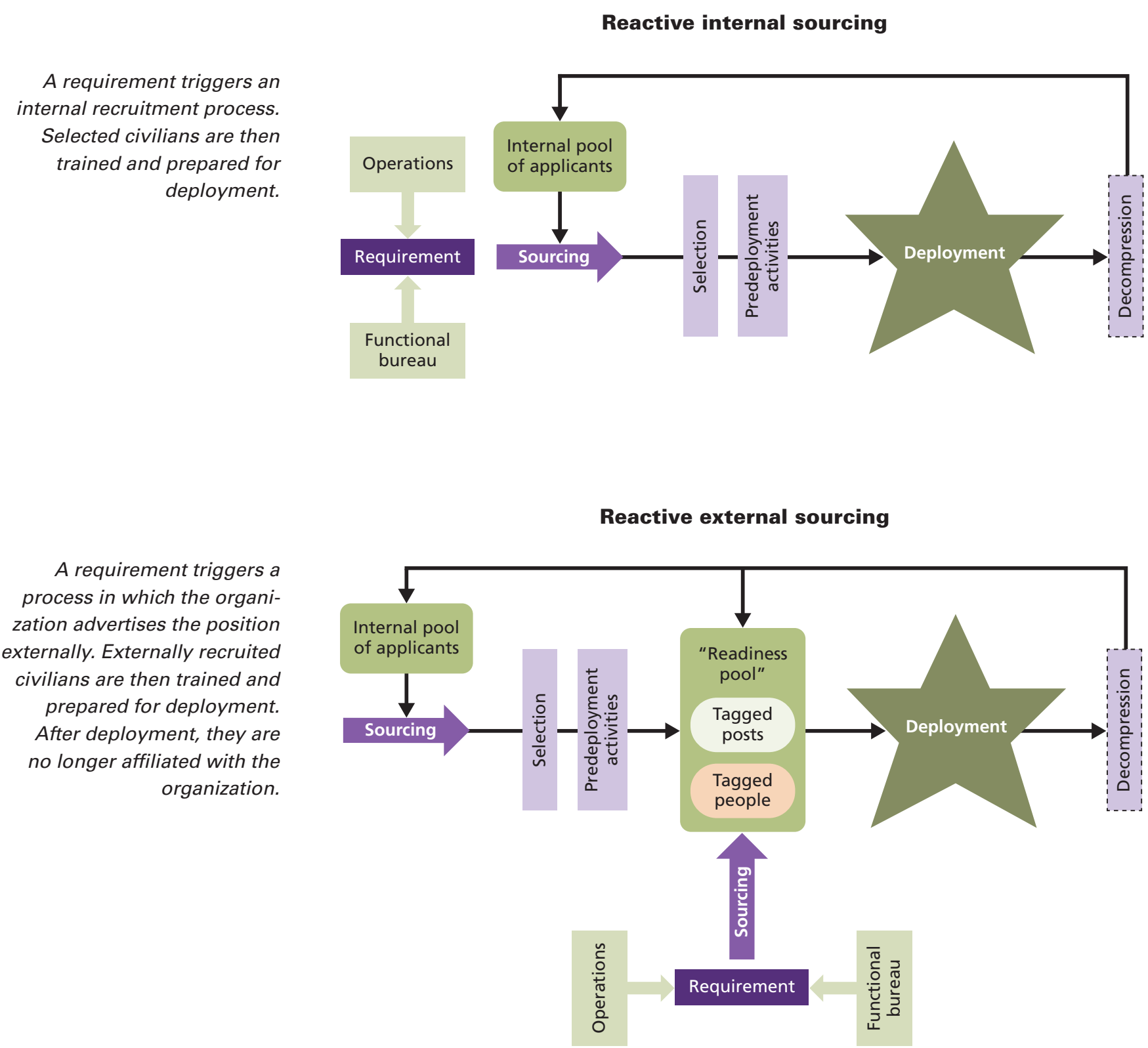


Proactive internal sourcing

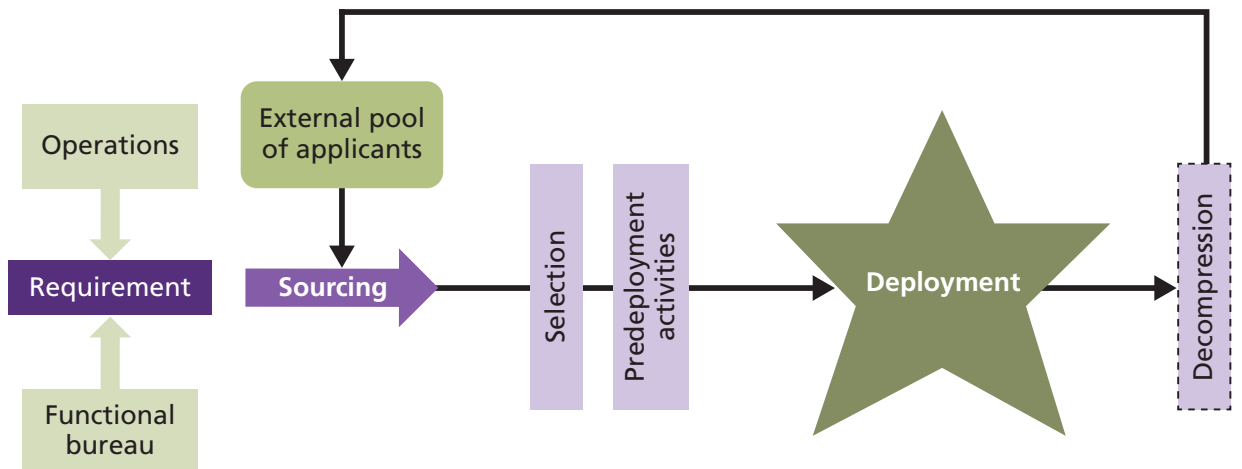

Deployable civilians internal to the organization are identified, trained, and prepared for deployment. When a requirement is identified, civilians with matching capabilities are drawn from this readiness pool.

\section{Proactive external sourcing}

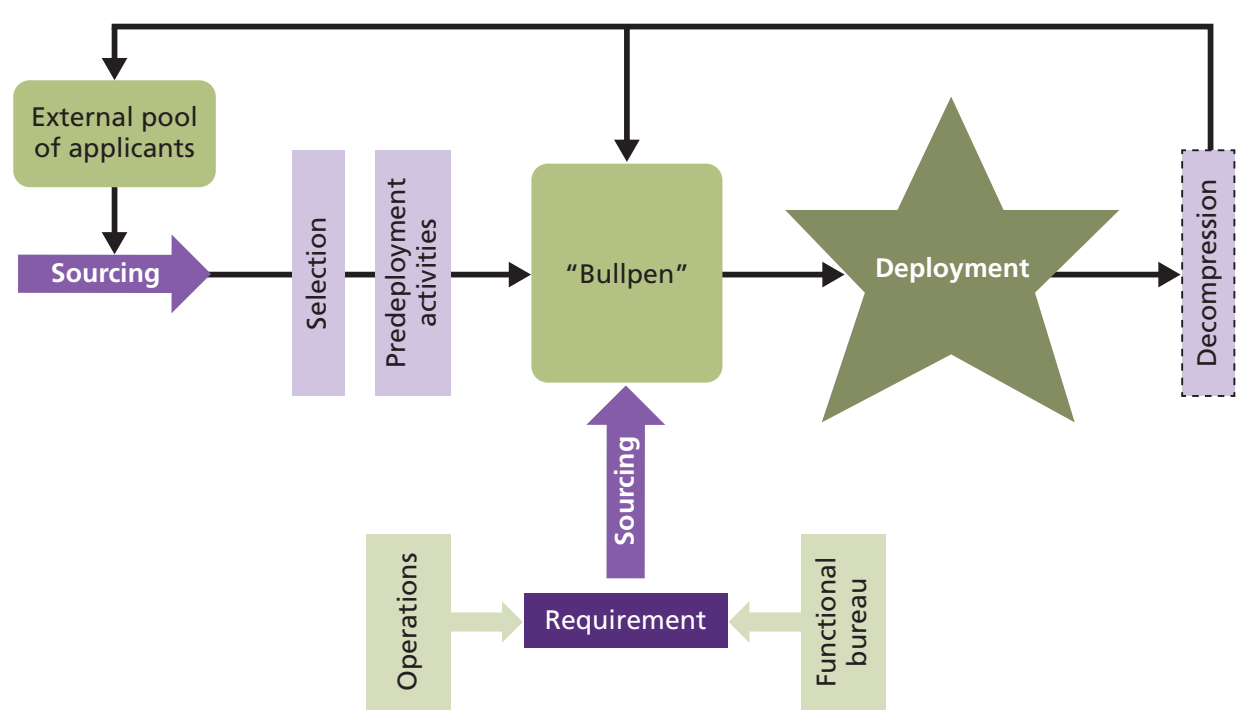

Deployable civilians external to the organization are recruited according to forecasted needs, trained, and prepared for deployment. They then enter a "bullpen" and wait to be called for duty. When a requirement is identified, civilians with matching capabilities are drawn from the bullpen and their pay and benefits are activated. 


\title{
Toward a Forward-Looking Model for DoD Civilian Deployment
}

\author{
Champion Expeditionary Civilian Capabilities
}

The non-DoD organizations studied had invested in efforts to raise awareness of their deployable civilian capabilities. With advocacy among senior leaders and recognition programs for civilians who have deployed, DoD could better promote the benefits of expeditionary civilians among the combatant commands and improve career incentives for civilians to deploy.

\section{Establish Joint-Level Oversight of Operations}

DoD has several options for designating a joint organization to oversee its expeditionary civilian workforce, each with benefits and drawbacks. However, a centralizing responsibility for recruiting, training, and tracking will provide DoD with a real-time, enterprise-wide view of available civilian capabilities.

\section{Adopt a Tiered Sourcing Approach}

Combatant commands will view expeditionary civilians as a reliable capability only if these personnel can deploy quickly. Quick-turn requirements are best served by a proactive sourcing model, while less urgent or emerging requirements could be met by a reactive sourcing model. Combining these two approaches will help DoD meet the widest range of mission needs.

\section{Assess Potential Mission Requirements and the Relative Costs of Deploying Different Types of Personnel}

Using a range of hypothetical contingencies, force-size requirements, and historical data, DoD should continue to identify candidates with in-demand skill sets and forecast the need for deployable civilian capabilities across a range of missions. In terms of cost, deployable civilians may not offer savings in all scenarios; in some cases, it may be more cost-effective to deploy military or contractor personnel. With a better understanding of these relative costs, DoD will be better able to allocate personnel across its entire workforce and mission set.

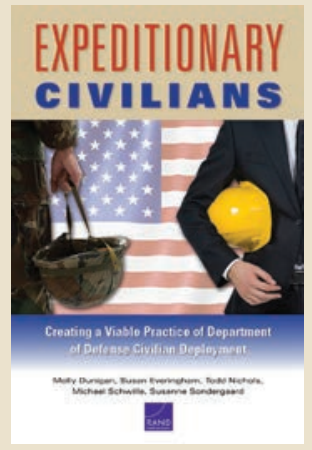

This brief describes work done in the RAND National Defense Research Institute and documented in Expeditionary Civilians: Creating a Viable Practice of Department of Defense Civilian Deployment, by Molly Dunigan, Susan S. Everingham, Todd Nichols, Michael Schwille, and Susanne Sondergaard, RR-975-OSD, 2016 (available at www.rand.org/t/RR975). To view this brief online, visit www.rand.org/t/RB9911. The RAND Corporation is a research organization that develops solutions to public policy challenges to help make communities throughout the world safer and more secure, healthier and more prosperous. RAND is nonprofit, nonpartisan, and committed to the public interest. RAND's publications do not necessarily reflect the opinions of its research clients and sponsors. RAND ${ }^{\circledR}$ is a registered trademark. ( $\odot$ RAND 2016.

Limited Print and Electronic Distribution Rights: This document and trademark(s) contained herein are protected by law. This representation of RAND intellectual property is provided for noncommercial use only. Unauthorized posting of this publication online is prohibited. Permission is given to duplicate this document for personal use only, as long as it is unaltered and complete. Permission is required from RAND to reproduce, or reuse in another form, any of our research documents for commercial use. For information on reprint and linking permissions, please visit www.rand.org/pubs/permissions. 